\title{
Synthetic Studies on Carbohydrate Antibiotics
}

\section{Part I. Synthesis of 6-Deoxy-D-xylo-Hexofuranos-5-ulose}

\author{
By Minoru Nakajima and Shozo TAKahashi ${ }^{*}$ \\ Department of Agricultural Chemistry, Faculty of Agriculture, Kyoto \\ University, Kyoto, *Pesticide Research Institute, \\ Kyoto University, Kyoto \\ Received May 31, 1967
}

\begin{abstract}
New synthetic methods for the preparation of 6-deoxy-1,2-O-isopropylidene- $\alpha$-D- $x y l 0$ hexofuranos-5-ulse (VIa) were described.
\end{abstract}

The general synthetic method of 6-deoxyhexos-5-ulose was the acid-catalyzed conversion of 6-deoxy-hex-5-enoses and some of them have been synthesized by this method. ${ }^{1 \sim 4}$ ) The synthetic studies of stereoisomers of 6deoxy-hexos-5-ulose are of interest in order to investigate the possible formation of 6-deoxyD-arabino-hexo-furanos-5-ulose (I), ${ }^{*}$ the sugar component of hygromycin A. Although this

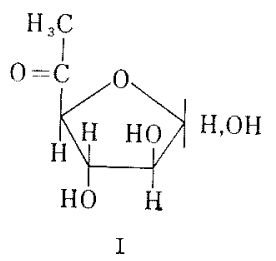

particular hexosulose has not yet been isolated from the hydrolysis product of hygromycin A, the hexosulose in the antibiotic was confirmed by preparation of L-fucose diethylmercaptal

1) H. Ohle and L. Vargha, Chem. Ber., 62, 2425 (1929).

2) B. Helferich and E. Himmen, ibid., 62, 2136 (1929).

3) A. Müller, ibid., 64, 1820 (1931).

4) H. Ohle and R. Deplanque, ibid, 66, 12 (1933).

* The nomenclatures of hexosuloses and unsaturated sugars were referred to "Rules of Carbohydrate

Nomenclature", J. Org. Chem., 28, 281 (1963) and

"Unsaturated Sugars", Advances in Carbohydrate Chem., 20, 67 (1965). and 5,6-dideoxy-arabino-hexose diethylmercaptal, which gave propionaldehyde on sodium metaperiodate oxidation. ${ }^{5 !}$

The present communication reports new synthetic routes to 6-deoxy-1,2-O-isopropylidene- $\alpha$-D- $x y l o$-hexofuranos-5-ulose (VIa) starting from 1,2-O-isopropylidene- $\alpha$-D-glucofuranose. One route involved selective oxidation of hydroxyl group at C-5 in 6-deoxy-1,2-Oisopropylidene- $\alpha$-D- $x y l o$-hexofuranose $(\mathrm{Va})$ and the other was a devised method of the usual preparation of 6-deoxy-hexos-5-uloses, conversion of enofuranoside into hexos-5-ulose.

3-O-Acetyl-1, 2-O-isopropylidene- $\alpha$-D-glucofuranose (II) was obtained by partial hydrolysis of 3-O-acetyl-1,2:5,6-di-O-isopropylidene$\alpha$-D-glucofuranose. ${ }^{6}$ This compound (II) was treated with $p$-tolylsulfonyl chloride in pyridine to give $3-\mathrm{O}$-acetyl-6-O-( $p$-tolylsulfonyl)1,2-O-isopropylidene- $\alpha$-D-glucofuranose (III). Substitution of $p$-tolylsulfonyloxy group with iodine was carried out with sodium iodide in acetone in a sealed tube to give 3-O-acetyl6-deoxy-6-iodo-1, 2-O-isopropylidene- $\alpha$-D-glucofuranose (IVa). The product (IVa) was hydrogenated neither over Raney nickel in methanol nor over Raney nickel with Amber-

5) R. L. Mann and D. O. Woolf, J. Am. Chem. Soc., 79, 120 (1957).

6) K. Josephson, Ann. Chem., 472, 217 (1929). 


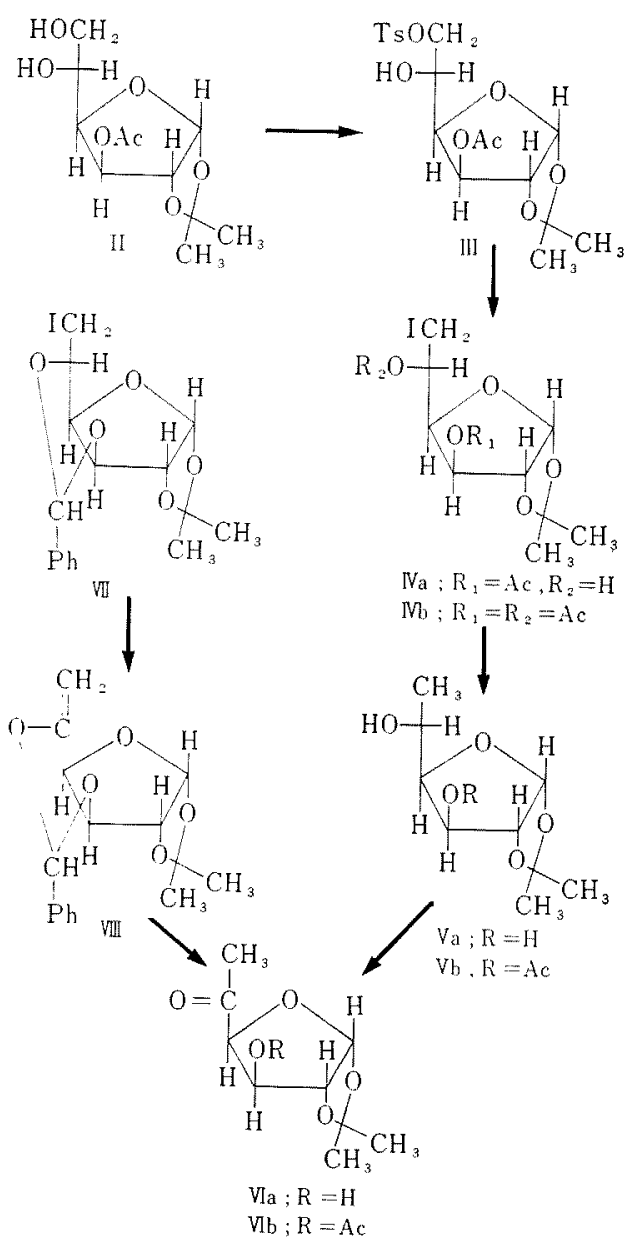

lite IR-45. On hydrogenation over Raney nickel after addition of triethylamine, however, the iodide (IVa) absorbed 2 moles of hydrogen to give not 3-O-acetyl-6-deoxy-1,2O-isopropylidene- $\alpha$-D-glucofuranose $(\mathrm{Vb}$ ) but 6-deoxy-1,2-O-isopropylidene- $\alpha$-D-glucofuranose (Va). ${ }^{7,81}$ Thus an attempt to oxidize 3-Oacetyl-6-deoxy-1, 2-O-isopropylidene- $\alpha$-D-glucofuranose $(\mathrm{Vb})$ to 3-O-acetyl-6-deoxy-1, 2-O-iso-

7) K. Freudenberg, H. Eich, C. Knoevenagel and W. Westphal, Chem. Ber., 73, 441 (1940).

8) A. S. Meyer and T. Reichstein, Helv. Chim. Acta, 29, 152 (1946). propylidene- $\alpha$-D- $x y l o$-hexofuranos-5-ulose (VIb) was discarded. The 6-deoxy-glucofuranose (Va) was also prepared by hydrogenation of 3,5-di-O-acetyl-6-deoxy-6-iodo-1, 2-O-isopropylidene- $\alpha$-D-glucofuranose (IVb) over Raney nickel with methanolic sodium hydroxide in methanol. ${ }^{\text {') }}$

Second attempt was selective oxidation of hydroxyl group at $\mathrm{C}-5$ in 6-deoxy-1,2-0-isopropylidene- $\alpha$-D-glucofuranose (Va). It has been known hydroxyl at C-3 in glucofuranose derivatives is resistant to usual oxidants, such as chromium trioxide. ${ }^{101}$ When the compound (Va) was kept with chromium trioxide in pyridine for 4 days at room temperature, hexofuranos-5-ulose (VIa) was obtained in a high yield. This compound (VIa) was also obtained through another synthetic route. 3,5-O-Benzylidene-6-deoxy-6-iodo-1, 2-O-isopropylidene- $\alpha$-D-glucofuranose (VII) obtained from $1,2-\mathrm{O}$-isopropylidene- $\alpha$-D-glucofuranose $\quad$ was treated with silver fluoride in pyridine to 3,5 O-benzylidene-6-deoxy-1, 2-O-isopropylidene- $\alpha$ D- $x$ ylo-hex-5-enose (VIII). ${ }^{11,12)}$ This enose (VIII) gave the hexofuranos-5-ulose (VIa) by removing the 3,5-benzylidene group in an acidic medium.

\section{EXPERIMENTAL}

Melting points were not corrected. Optical rotations were measured on a photo-magnetic direct reading polarimeter Model OR-20, Yanagimoto Co. LTD NMR spectrum was measured on a Varian Associates A-60 spectrometer. The infrared spectra were taken in nujol mull.

3-0-Acetyl-6-0-( $p$-toly lsulfonyl $)-1,2-0$-isopropy lidene- $\alpha$-D-glucofuranose (III). $\quad p$-Tolylsulfonyl chloride $(4.2 \mathrm{~g})$ in dry choroform $(30 \mathrm{ml})$ was added dropwise into a pyridine solution $(30 \mathrm{ml})$ of 3-0-acetyl$1,2-\mathrm{O}$-isopropylidene- $\alpha-\mathrm{D}$-glucofuranose (II) $(5.2 \mathrm{~g})$ at

9) E. Vischer and T. Reichstein, ibid., 27, 1332 (1944).

10) R. F. Nutt, B. Arison, F. W. Holly and E. Walton, J. Am. Chem. Soc., 87, 3273 (1965).

11) A. S. Meyer and T. Reichstein, Helv. Chim. Acta, 29, 139 (1946).

12) B. Helferich and R. Mittag, Chem. Ber, 71 1585 (1938). 
$0^{\circ} \mathrm{C}$. The reaction mixture was kept at room temperature for 2 days. Pyridine was distilled off in vacuo and the residue was extracted with ether. The ethereal layer was washed with water, dried over sodium sulfate, and filtered, and the filtrate was evaporated to dryness. Yellow oil thus obtained was crystallized from ether-n-hexane to give colorless needles, m.p. $120 \sim 121^{\circ} \mathrm{C}(7 \mathrm{~g}, 84.3 \%)$. Anal. Found: $\mathrm{C}, 52.10 \%$; $\mathrm{H}, 6.03 \%$ Calcd for $\mathrm{C}_{18} \mathrm{H}_{24} \mathrm{O}_{9} \mathrm{~S} ; \mathrm{C}, 51.91 \% ; \mathrm{H} .5 .81 \%$. 3-0-Acety 1-6-deoxy-6-iodo-1, 2-0-isopropylideneo-D-glucofuranose (IVa). 3-O-Acet y1-6-O-( $p$-tolylsulfonyl)-1,2-O-isopropylidene- $\alpha$-D-glucofuranose (III) (2 g) and sodium iodide ( $1 \mathrm{~g}$ ) were dissolved in dry acetone $(15 \mathrm{ml})$. The solution was heated in a sealed tube at $60^{\circ} \mathrm{C}$ for 24 hrs. Separated sodium $p$-tolylsulfonate was filtered off and the filtrate was evaporated to dryness. The residue was dissolved in chloroform, washed with aqueous sodium thiosulfate and water. The chloroform solution was dried over calcium chloride and the solvent was distilled off under reduced pressure. The residue was colorless oil ( $1.8 \mathrm{~g}$, $98 \%$ ), but showed single spot on silica gel t.l.c. (developing solvent; dry chloroform-acetone, 9.5:0.5. Spray reagent; ammonium metavanadiate in $50 \%$ $\mathrm{H}_{2} \mathrm{SO}_{4}$ ).

6-Deoxy-1, 2-0-isopylidene- $\alpha$-D-glucofuranose (Va). Into a methanol solution $(40 \mathrm{ml})$ of 3 -O-acetyl 6-deoxy-6-iodo-1, 2-O-isopropylidene- $\alpha$-D-glucofuranose (IVa) $(1.8 \mathrm{~g})$, Raney nickel $(3 \mathrm{ml})$ and $5 \%$ methanolic sodium hydroxide $(15 \mathrm{ml})$ were added. The reaction mixture was shaken with hydrogen until no more absorption occurred. The solution was filtered and the filtrate was neutralized with diluted hydrochloric acid. Evaporation of the filtrate gave a colorless oil which was crystallized from ether-n-hexane. Recrystallization from carbon tetrachloride gave color: less leaflets $(1 \mathrm{~g}, 72 \%)$, m.p. $87 \sim 89^{\circ} \mathrm{C}$. Anal. Found; C, 52.72\%; H, 7.96\%, Calcd. for $\mathrm{C}_{9} \mathrm{H}_{10} \mathrm{O}_{5} ; \mathrm{C}, 52.9 \%$; H, $7.90 \%$. vOH $3320 \mathrm{~cm}^{-1}$, vOH $3450 \mathrm{~cm}^{-1}$. No ester band.

6-Deoxy-1, 2-0-isopropylidene- $\alpha$-D-xylo-hexofuranos-3-ulose (VIa). 6-Deoxyl-1,2-O-isopropylidene- $\alpha$ D-glucofuranose ( $\mathrm{Va})(0.6 \mathrm{~g}$ ) was dissolved in pyridine $(20 \mathrm{ml})$ and chromium trioxide $(0.5 \mathrm{~g})$ was added. The reaction mixture was kept at room temperature with occasional shaking for 4 days. The mixture was filtered and the pyridine solution was evaporated to dryness in vacuo. The oily product was crystallized from benzene- $n$-hexane to give colorless needles $(0.5 \mathrm{~g}, 83 \%)$, m.p. $96 \sim 97^{\circ} \mathrm{C}$. voH $3500 \mathrm{~cm}^{-1}, \nu \mathrm{C}=0$ $1720 \mathrm{~cm}^{-1}$. The NMR spectrum (in deuteriochloroform solution, with tetramethylsilane as internal reference) showed methyl proton signals at $7.7 \tau\left(\mathrm{H}_{3} \mathrm{C}-\mathrm{C}=\mathrm{O}\right.$, singlet), 8.60 and $8.70-\left(\left(\mathrm{CH}_{3}\right)_{2}=\mathrm{C}=\right)$, and an anomeric proton signal at $3.92 \div\left(\mathrm{H}-\mathrm{C}_{1}-\right.$, doublet, $\mathrm{J}_{1,2}=$ 4.0 c.p.s.). Anal. Found; C, $53.53 \% ; \mathrm{H}, 7.02 \%$ Calcd. for $\mathrm{C}_{9} \mathrm{H}_{14} \mathrm{O}_{5} ; \mathrm{C}, 53.46 \% ; \mathrm{H}, 6.98 \%,[\alpha]_{\mathrm{D}}^{16}-104^{\circ}(c$, 0.75 in chloroform).

3,5-0-Benzy lidene-6-deoxy-1, 2-0-isopropy lidene$\alpha-D-x y l o$-hex-5-enose (VIII). 3,5-O-Benzylidene-6iodo-1,2-O-isopropyliclene- $\alpha$-D-glucofuranose (VII) $(1.2 \mathrm{~g})$ was shaken with dry silver fluoride $(1.2 \mathrm{~g})$ in dry pyridine $(10 \mathrm{ml})$ for 15 hrs. Ether was added, filtered and distilled off the solvent in vacuo. The residue was crystallized from methanol to give colorless blocks $\left(0.5 \mathrm{~g}, 60^{\circ}\right)$, m.p. $123 \sim 125^{\circ} \mathrm{C}$. $\nu \mathrm{C}=0$ $1675 \mathrm{~cm}^{-1}$. Anal. Found; C. $66.04 \% ; \mathrm{H}, 6.32 \%$ Calcd. for $\mathrm{C}_{16} \mathrm{H}_{18} \mathrm{O}_{5} ; \mathrm{C}, 66.19 \% ; \mathrm{H}, 6.25 \%$.

6-Deox $y-1,2-0$-isopropylidene- $\alpha$ - D-xylo-hex of uranos-5-ulose (VIa) from (VIII). Acetic acid solution $(20 \mathrm{ml})$ of 3,5-O-benzylidene-6-deoxy-1,2-O-isopropylidene- $\alpha$-D-xylo-hex-5-enose (VIII) $(0.4 \mathrm{~g})$ and $0.91 \mathrm{~N}$ sulfuric acid $(8 \mathrm{ml})$ was kept at room temperature for 90 hrs. The solution was neutralized with diluted sodium hydroxide and evaporated in vacuo to dryness. The oily product was dissolved in chloroform and passed through silisic acid column ( $10 \mathrm{~g}$ ). From the eluate, colorless syrup was obtained and crystallized from benzene- $n$-hexane $(0.14 \mathrm{~g}, 50 \%)$, m.p. $96 \sim 97^{\circ} \mathrm{C}$. Mixed melting point with authentic sample (VIa from Va) showed no depression.

Acknowledgment. The authors wish to express their sincere thanks to Professor $\mathrm{T}$. Mitsui and associates, Department of Agricultural Chemistry, Kyoto University, for microanalysis, and to Dr. T. Shingu, Department of Pharmacy, Kyoto University, for NMR datum. 